\title{
A COMPARATIVE STUDY OF DISTAL RADIUS FRACTURES MANAGED BY LIGAMENTOTAXIS VERSUS BUTTRESS PLATING
}

\author{
Supreeth Nekkanti1, Ravi Kiran H. G'2, Kanthimathi B3, Arunodhaya Siddartha ${ }^{4}$, Dinesh Ram Kumar ${ }^{5}$
}

${ }^{1}$ Senior Resident, Department of Orthopaedics, JSS Hospital.

${ }^{2}$ Assistant Professor, Department of Orthopaedics, JSS Hospital.

${ }^{3}$ Professor, Department of Orthopaedics, Annamalai Univeristy.

${ }^{4}$ Assistant Professor, Department of Orthopaedics, JSS Hospital.

5Junior Resident, Department of Orthopaedics, JSS Hospital.

ABSTRACT: The fracture of the distal end of radius was first identified by Sir Abraham Colles. With the increase in high velocity trauma, there has been an observed increase in the incidence and fracture patterns of the distal radius.

MATERIALS AND METHODS: We conducted a prospective on distal radius fractures with 132 patients. All cases of distal radius fractures were considered between the age group of 20 and 70 years. Frykmans classification was used to classify the fractures. The patients were followed up every three weeks following surgery.The patients were assessed subjectively and objectively using New York Hospital Wrist Scoring system.

RESULTS: Our study showed that anatomical and functional results were excellent in $35.7 \%$ of the patients versus $25 \%$ of those patients treated by external fixation. 30.3\% of our patients managed by internal fixation had good functional outcome at the end of one year follow-up versus $43.4 \%$ of them treated with external fixation. $25 \%$ of patients treated by internal fixation had fair results while $13.1 \%$ of the patients managed by external fixation had fair results. Poor results were observed in $8.9 \%$ of patients managed by internal fixation as compared to $18.4 \%$ of them managed by external fixator. The fair and poor results were due to inability to maintain accurate articular reduction and congruity of the distal radius using the external fixator. Potential complications like pin tract infection and loosening could also be attributed towards poor scores while using external fixation.

CONCLUSION: The incidence of complications and poor results in internal fixation are fewer when compared to external fixation in this study. Patients managed with buttress plating had better functional outcome and returned to their daily routine earlier than those patients managed with ligamentotaxis.

KEYWORDS: Distal Radius Fractures, Ligamentotaxis, Buttress Plating, Comparative Study.

HOW TO CITE THIS ARTICLE: Supreeth Nekkanti, Ravi Kiran H. G, Kanthimathi B, Arunodhaya Siddartha, Dinesh Ram Kumar. "A Comparative Study of Distal Radius Fractures Managed by Ligamentotaxis Versus Buttress Plating”. Journal of Evolution of Medical and Dental Sciences 2015; Vol. 4, Issue 92, November 16; Page: 15775-15781, D0I: 10.14260/jemds/2015/2280.

INTRODUCTION: The fracture of the distal end of radius was first identified by Sir Abraham Colles in 1814.[1,2] This was an extra-articular fracture and occurred in elderly individuals with osteoporotic bones.[1] $\mathrm{He}$ described six classical deformities and advocated plaster cast as the treatment of choice. With the increase in high velocity trauma, there has been an observed increase in the incidence and fracture patterns of the distal radius. Younger individuals with good bone stock with intra-articular involvement have been more common.

Plaster application in these fractures results in a lapse of functionality of the wrist and unsatisfactory cosmetic finish. Radial shortening, finger stiffness and wrist joint arthritis are common sequel. Many methods of treatment have been tried to circumvent these problems.

Financial or Other, Competing Interest: None.

Submission 31-10-2015, Peer Review 02-11-2015,

Acceptance 07-11-2015, Published 16-11-2015.

Corresponding Author:

Dr. Supreeth Nekkanti,

No. 160, 11 $1^{\text {th }}$ Cross, $5^{\text {th }}$ Main,

$1{ }^{\text {st }}$ Stage, NGEF Layout, Nrupatunganagar,

Nagarbhavi,

Bangalore-560072.

E-mail: drsupreethn@gmail.com

DOI:10.14260/jemds/2015/2280.
Percutaneous fixation of the displaced fragment under radiological control, supplemented by external fixator has given excellent results. Volar or dorsal rim fractures of distal radius demand the need for buttress plate fixation. The results of closed reduction followed by immobilization in external fixation and buttress plating provide a viable and better alternative to physiologically young patients whose work schedule places a heavy load on the wrist.

Thus the upcoming modality of treatment of unstable fractures of distal end of radius with intra-articular extension is either by external fixation or buttress plating.

The common indications for surgical fixation of distal radius include unstable extra-articular fractures with significant comminution, comminuted intra-articular fractures, compound fractures, fractures that fail to maintain reduction with POP splint. Buttress plating is ideally done to provide a buttress against compression.

Pathological Anatomy of Distal Radius Fracture: Colles fracture is a complete transverse break of the distal radius with dorsal displacement of the distal fragment. A considerable number of fractures showed comminution, impaction or extension into the radio-ulnar or radio-carpal joint. This is the definiton by Robert W Bacron and Kurtake in the study Workmans Compensation Board in New York. 
Normal displacement as described by Sir Reginald Watson Jones areImpaction, lateral displacement, lateral rotation, dorsal displacement, dorsal rotation, supination tilt of the distal fragments.[3]

A considerable number of fractures are also associated with ulna styloid fractures. SIR John Charnley in his book "Closed treatment of common fractures" described the fracture as a fracture of cancellous bone and it is bound to collapse at the fracture site.[4] The immobilization of the fracture is a matter of convenience as suggested because the normal functional position of the wrist is extension, whereas the fracture is immobilized in flexion, pronation and ulnar deviation.

Charnley explained that the intact periosteum on the dorsal aspect which helps as a soft tissue hinge is the one which must be maintained under tension.[5] $\mathrm{He}$ also emphasized the need for disimpaction of fragments by increasing the dorsal angulations and applying traction. According to this explanation by Sir John Charnley it is easy to obtain reduction by external fixation of distal radius fractures. ${ }^{[5]}$

Biomechanics: The global motion of the wrist is composed of flexion, extension and radio-ulnar deviation at the radio carpal joint and axial rotation around distal radio-ulnar joint.

The forearm accounts for most of the rotation (Around $140^{*}$ ). The motion of radio-carpal joint is flexion-extension of 80 and 90 degrees respectively. This amount of motion is possible as a result of complex arrangement between the two carpal rows.

During the flexion and extension each carpal row angulates in the same direction with nearly equal amplitude and ina synchronous fashion. During radio-ulnar deviation, however the proximal row exhibits a secondary angulation in the sagittal plane to synchronous motion occurring in the coronal plane. This conjugates rotation by varying the length and contour of the proximal row and allows for extensive excursion of the wrist while maintaining stability around a longitudinal axis. This has been described as the Variable Geometry of the proximal carpal row. When this mechanism has been disrupted by fracture or ligamentous injury the wrist becomes destabilised.

Mechanism of Injury: The injury most often occurs due to fall on an outstretched hand in osteoporotic elderly women though other type of violence such as automobile accidents and direct violence do produce comminuted distal radius fracture. The amount of force required to produce fractures experimentally in dorsiflexion of wrist varies from $105 \mathrm{~kg}$ to $440 \mathrm{~kg}$ with a mean of $195 \mathrm{~kg}$ for women and $228 \mathrm{~kg}$ for men. Fractures of the distal radius are produced when the dorsiflexion of wrist varies from 40 to 90 degrees, less amount of force being required at smaller angles.[6]

Radial displacement and dorsal angulation are two principal deformities. Bending movement force induces compression stress which results in dorsal comminution of fracture line proceeding along $45^{*}$ shear stress lines. Cancellous bone is compacted with further reduction in stability. A high tensile loading to palmar carpals is essential to transmit the load to anterior cortex. ${ }^{[7]}$
As the pronated hand strikes the ground the radius is fractured and residual force tends to drive the distal fragment backward. Moderate backward angulation results but further displacement produces tension on the fibrocartilage to the head of the ulna. This results in more angulation and precludes backward displacement or radial deviation. If the force of injury is sufficiently great the sudden tension on the fibro-cartilage complex may result in avulsion fracture of its attachment usually the ulna styloid or from its radial attachment or both.

Radiologoical Anatomy: Radiographic measurements have formed the foundation of evaluation of not only the injury but also outcome of treatment. Standard X-ray views areanteroposterior, lateral and oblique. Antero-posterior view shows the concave inferior articular surface of lower end of radius extending down to the tip of styloid process.

Volar tilt/inclination [1]: (Fig.1) In the sagittal view, a line connecting the distal most point of the dorsal and volar rims. The angle that this line creates with a line perpendicular to the longitudinal axis of the radius reflects the volar inclination. Average inclination is $11^{*}\left(4-22^{*}\right)$.

Radial tilt/inclination [1]: (Fig.1) In the anteroposterrior view, inclination of the distal end of radius is represented by the angle formed by a line drawn from the tip of the radial styloid to the ulnar corner of the articular surface of the distal end of radius and a line drawn perpendicular to the longitudinal axis of radius. The average inclination is $21^{*}\left(13-30^{*}\right)$.

Radial length [1]: (Fig.1) It is measured on anteroposterior X-ray. It represents the distance between a line drawn at the tip of the styloid process, perpendicular to the long axis of the radius and a second line at the level of the distal articular surface of ulnar head. Normally ranges between 11 to $12 \mathrm{~mm}$.

Ulnar variance [1]: (Fig. 1) The vertical distance between the distal ends of the medial corner of the radius and ulna head represents the ulnar variance.

MATERIALS AND METHODS: A hundred and thirty two patients with fracture distal end of radius with intra-articular extension were included in the study. All of these patients were chosen from emergency department and from our orthopaedic out-patient department. The patients were followed up for a minimum of sixteen weeks.

All the patients included in study were classified and studied as per Frykman's classification of distal radius fractures and were treated as in-patients. Patients were managed with a uniaxial distraction system consisting of distraction rod, beta clamps, K-wires/Schanz pins and an Allen key.

After removal of the external fixator (3-6 weeks of fixation), the patients were put in continuous passive motion and early wrist movement was encouraged.

Surgical Technique (External Fixator): Patient placed supine position with the affected limb abducted at shoulder and wrist placed on a side table. 
PROCEDURE: (Fig. 2) External fixator was applied in the operation theatre under sterile conditions. The pins used for radius were of $3.5 \mathrm{~mm}$ Schanz pins and that for metacarpal were $2.5 \mathrm{~mm}$ Schanz pins. After scrubbing, painting, draping (With or without pneumatic tourniquet), a small incision was taken on the dorsolateral aspect of the forearm about $3-5 \mathrm{~cm}$ proximal to the fracture site. $[6,7,8]$ Lateral cutaneous nerve of the forearm was identified. $2.7 \mathrm{~mm}$ drill but was used for pre drilling. $3.5 \mathrm{~mm}$ Schanz pin was inserted. Second pin site was selected beyond mid forearm proximally (Greater this distance from the first pin in distal end of radius $3-5 \mathrm{~cm}$ proximal to fracture site, more stable the fixation).

Two Schanz pins were passed to the $2^{\text {nd }}$ metacarpal into the base and neck of the second metacarpal. Both these pins were passed on the lateral surfaces. The radial and metacarpal pins were connected by an external connecting rod. Reduction was achieved under image intensifier control. The best position seemed to be in ulnar deviation of forearm. ${ }^{[7,8,9,10]}$

Early pin tract infection if any was treated with antibiotics. Fixator was left in situ for 6-12 weeks. Fixator removal was considered only after clinical and radiological evidence of fracture healing.

After fixator removal a splint was given for another 2 weeks that was to be removed during exercises. Range of motion exercises for fingers, wrist and elbow were advised.

\section{SURGICAL TECHNIQUE (INTERNAL FIXATION): Buttress plating.}

Procedure: Volar approach (Fig.3): After painting and draping, a longitudinal incision of about $7.5 \mathrm{~cm}$ long was made on the radio-volar aspect of the distal forearm. The plane between the flexor carpi radialis and the Palmaris longus was developed. The flexor pollicis longus tendon was retracted radial ward and the median nerve and the other tendons were retracted ulnarward. The fibres of the pronator quadratus were erased from their origin on the radius and fracture was exposed.[11,12,13]

Dorsal approach (Fig.3): After painting and draping, an $8 \mathrm{~cm}$ longitudinal incision was made on the dorsum of the wrist, crossing the wrist along the midpoint of radial and ulnar styloids. The incision begins $3 \mathrm{~cm}$ proximal to wrist joint and ends about $5 \mathrm{~cm}$ distal to it. Once the fascia is dissected, the retinaculum is exposed. The retinaculum is divided to expose the fourth extensor compartment containing the extensor digitorum communis and extensor indicis tendons. ${ }^{[13,14]}$ Fracture was reduced and a buttress plate was contoured so that, when it is applied and fixed to the proximal fragment, the distal transverse part will act as a buttress and hold the fracture reduced. A minimum of two screws were inserted in the proximal fragment.

In this study volar approach was found to be more advantageous because of the smooth and flat surface of bone where the plate could be placed well. A better buttress effect was provided against volar collapse. There was also no evidence of tendon rupture in this approach.[13,14]

Post operatively, the upper limb was elevated for 24 hours with monitoring of neurovascular status. Early motion of digits, elbow and shoulder was encouraged
Patients were assessed subjectively and objectively. A detailed questionnaire was prepared for each patient to evaluate factors like pain, functional limitations and occupational hindrance. New York wrist scoring system (Table. 1) was used..

DISCUSSION: The management of distal radius fractures has changed considerably since Cassebaum (1950) supported Abraham Colles statement that a patient with a colles fracture will not have pain or serious functional disability despite considerable deformity. This is no longer acceptable. Mc Queen and Caspers (1988) have shown a clear correlation between anatomical reduction and functional results.[1] Secondary reconstruction is difficult and repeated manipulations appear to increase the risk of algodystrophy. It therefore seems that fractures of the distal radius should be treated by principles usually applied to other articular fractures. Intra-articular fractures with a step of over $2 \mathrm{~mm}$ in the radiocarpal joint inevitably result in osteoarthritis and functional impairment. It is therefore important to reconstruct the joint surface and make it congruent. Plating ( $\mathrm{T}$ plate) enables both the radiocarpal and radioulnar joints to be perfectly restored.

Distal radius fractures account for $20 \%$ of all fractures and are only second to hip fractures in terms of incidence in the elderly population.[15] Fragility fracture of the distal part of the radius is a major source of patient morbidity. of the 65 patients of unstable Colles fracture studied at Mayo's clinic, 53 were women and 7 men. The mean age was 63 years.[16] This indicates that distal radius fractures was more common in the geriatric age group. In our study $41(31.1 \%)$ of the patients were in the age group of 30 to 40 years.[Table.2] This shows that distal radius fracture is not necessarily confined to geriatric age group.[10]. Thus the incidence of distal radius fractures is increasing in the younger age group too.

In our study, Frykman's classification was used for classification of the fracture type. In our present series, the number of male patients was 79 versus 53 female patients. [Table. 3] The present lifetime risk of sustaining fracture is $15 \%$ for women and $2 \%$ for men. ${ }^{[15]}$ In our study there were $79(59.8 \%)$ male patients and 53(40.2\%) female patients indicating that the incidence of distal radius fractures is no longer limited to females.

In our series, right sided fractures were commoner than the left sided fractures. Eighty three patients $(62.9 \%)$ had injured their dominant hand versus $49(37.1 \%)$ who injured their non- dominant hand. Frykman type III (58 patients43.9\%) was the commonest fracture pattern observed in our study. The least presented type of fracture was that of Frykman type V (13 patients-9.8\%) [Table. 5]

W P Cooney, in his study of 65 patients of unstable Colles fracture found that 50 patients sustained injury due to fall on outstretched hand.[10] Six patients sustained a motor vehicle accident. No specific mechanism of injury was recorded in 4 patients.[10] Road traffic accidents were the main cause of injury. In our study, 88(66.7\%) patients suffered a road traffic accident while $44(33.3 \%)$ of them fell on their outstretched hand. 
This may lead us to think that road traffic accidents are proving to be the emergent cause of more complex distal radius fractures and to conclude that high energy trauma has surpassed self-fall as the major cause for distal radius fractures. All patients were followed for a minimum period of 16 weeks. For each visit, patient was evaluated clinically and radiologically and the final results were analysed using New York Orthopaedic Hospital Wrist Scoring system

Despite wide spread enthusiasm for plating, current literature does not demonstrate the clear benefit of plating. When a fracture is well reduced either technique will provide similar good results. In this study $42.4 \%$ of the patients were treated by internal fixation (Buttress plating) and $57.5 \%$ by external fixator.

A number of studies have reported favourable results with external fixation, although most of the studies were retrospective and, thus are difficult to interpret due to the heterogeneous group of patients with a variety of skeletal and soft tissue injuries. In a study by Jesse B. Jupiter, the incidence of complications was high ranging from 20 to $60 \% .^{[1,18]}$ The complications included infection of pin tract, radial sensory neuritis, reflex sympathetic dystrophy, stiffness of the wrist and fracture through the pin sites. Although improved techniques of insertion of pins, pre-drilling have reduced the problems related to pins, the potential for wrist stiffness still remains a concern. In a landmark study in 1979, Cooney et al.[10,17] reported only a slight loss of motion in patients who were followed for two years or more.[18]

The range of motion of the wrist that was reported by Clayburn. ${ }^{11}$ in 1987, who used a mobile external fixator, showed little, if any, improvement compared with the series of Cooney et al.[10] The measurements of wrist movements revealed mean dorsiflexion of $48^{*}$ compared with70* on the normal side. Mean palmar flexion was $28^{*}$ as compared with $90^{*}$ on uninjured side. The average supination and pronation was $44^{*}$ and $53^{*}$ respectively. The average ulnar and radial deviation at wrist were $20^{*}$ and $14 *$ respectively. [Table. 6]

The statistical figures show that anatomical and functional results were good were excellent in $35.7 \%$ of the patients versus $25 \%$ of those patients treated by external fixation. $30.3 \%$ of our patients managed by internal fixation had good functional outcome at the end of one year follow-up versus $43.4 \%$ of them treated with external fixation. $25 \%$ of patients treated by internal fixation had fair results while $13.1 \%$ of the patients managed by external fixation had fair results. Poor results were observed in $8.9 \%$ of patients managed by internal fixation as compared to $18.4 \%$ of them managed by external fixator. [Table. 7]

As studied by previous surgeons complications encountered in this study were in concurrence with the literature. $[1,4,10,11,12]$ The most common complications encountered in our series were pin tract infection, pin loosening and finger stiffness. In 10 patients pin tract infection was superficial and relieved by regular antiseptic dressings and antibiotics. Five patients had pin loosening for which surgery was revised. 8 patients had wrist pain after removal of external fixator which got relieved with analgesics and physiotherapy. Eight patients operated by buttress plate had finger stiffness.
The incidence of complications in internal fixation $(14.2 \%)$ is fewer compared to external fixation $(30.2 \%)$ in this study.

The operative management of these fractures is difficult. Preoperative planning, antero-posterior and lateral $\mathrm{X}$-rays are extremely helpful. The volar approach is most useful. The articular reconstruction should be supported by buttress plate. Although enthusiasm for operative approach for complex articular fractures of the distal end of radius is growing, serious complications including loss of fixation, neuritis of median nerve, reflex sympathetic dystrophy and infection of wound can occur even when surgeon is experienced.[10]

CONCLUSION: Current concepts of management of distal radius are trending towards early enthusiastic fixation to secure and maintain reduction and avoid late collapse. Thus distal radius fractures are now virtually segmented as a different entity. The different modalities of operative management for distal radius fractures are external fixator, percutaneous pinning and buttress plating.

Internal fixation with the use of buttress plate and screws allows more accurate treatment by giving good anatomical reduction. After reconstruction of the joint under direct vision and re-establishment of radial length, both intermediate and lateral columns can be buttressed. The plate is especially useful for very short fragments such as Barton's fracture. Early mobilisation can be started to achieve better outcomes.

This is a short term study on distal radius fractures with 132 patients which showed better functional outcome than ligamentotaxis and fewer complications. A longer multifactorial causative study may give us better understanding of this complex problem.

\section{Ethical Standards:}

1. The patients gave the informed consent prior being included into the study;

2. The study was authorized by the local ethical committee and was performed in accordance with the Ethical standards of the 1964 Declaration of Helsinki as revised in 2000 .

\section{BIBLIOGRAPHY:}

1. M.A.Nazar, R.Mansingh, R.S.Bassi, M.Wasim, Is there a Consensus in the management of Distal Radius Fractures? The Open Orthopaedics Journal Oct 2009, Bentham Open, Vol-3, 96-99.

2. G.R.Sennwald, Distal Radius Fracture, Palmar or Dorsal Approach? 1995, JHS, 20-A, 1021-27.

3. Sir John Charnley, The Closed treatment of Common Fractures 5Library of Congress Cataloging-inPublication Data, Hand surgery / edited by Richard A. Berger, Arnold-Peter C. Weiss.

4. Clayburn TA, Dynamic External Fixation for Comminuted Intra-articular Fracture of Distal End of Radius, Journal of Bone and Joint Surgery (Am), 1987, Vol 69 A, 248-254. 
5. Nakata R Y; Chand Y; Matiko JD, Frykman GK, Wood VE, External fixators for Wrist Fractures, A biomechanical and clinical study, Journal of Hand Surgery (Am), 1985, Vol 19, 845-851.

6. Webber S.C, Szabo R.M, Severely Comminuted Distal Radius Fracture As an Unsolved Problem. Complications associated with External Fixation and Pin and Plaster technique, Journal of Hand Surgery, 1986, Vol 11A, 157 165.

7. Melone CP, Articular Fractures of Distal Radius, Orthop.Clin, North America, 1984, Vol 15, 217-236.

8. William P.Cooney, III, MD, Ronald S Linscheid, M.D, External Pin Fixation for Unstable Colle's Fracture, Journal Of Bone and Joint Surgery, Sept 1979, Vol.61-A, No-6,840-845.

9. Jaiyoung Ryu MD, William P Cooney III, Functional Ranges of Motion of Wrist Joint, Journal of Hand Surgery, Vol 16A, No3, May 1991, 409-419

10. Richard Y.Kim, MD, and Melvin P Rosenwasser, MD, Internal Fixation of Distal Radius Fractures, Am J Orthop. 2007; 36(12 suppl): 2-7.

11. David H.Wei, Noah M Raizman, Unstable Distal Radius Fractures treated with External Fixation, Radial Column Plate, Volar Plate. A prospective randomised trial, July 2009, The Journal of Bone and Joint Surgery, Vol-91A, N0-7, 1568-77.

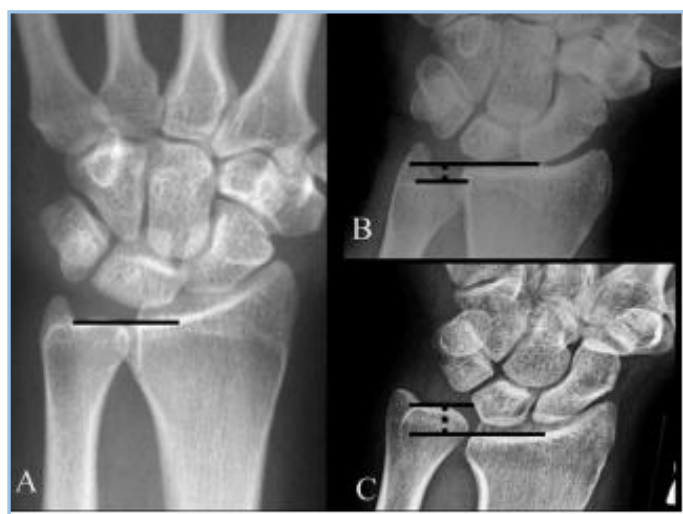

$$
\begin{aligned}
& \text { A-Neutral Variance } \\
& \text { B-Negative Variance } \\
& \text { C-Positive Variance }
\end{aligned}
$$

12. Arel Gereli, Comparison of Palmar Locking plate and Kwire Augmented External Fixation for Intra-articular and Comminuted Distal Radius Fracture, Dec 2009, ActaOrthopaedicTraumatolTurc 2010,Vol 44(3),212-219.

13. Fernando Deigo L, Jesse B Jupiter, Library of Congress, Fractures of Distal Radius: A Practical Approach to Management, 2nd edition.

14. P.L.O BROOS, I.A.M FOURNEAU, D.V.C.STOFFELEN, Fractures of Distal Radius, Current Concepts of treatment, Acta Orthopaedica Belgica, 2001,Vol67-3, 211-218.

15. JAMES W PRITCHETT, External Fixation Or Closed Medullary Pinning for Unstable Colles Fracture, British Journal of Bone and Joint Surgery, March 1995, Vol 77 B, No 2, 267-269.

16. David S. Ruch, MD, AnastasiosPapadonikolakis, MD, Volar versus Dorsal Plating in the Management of IntraArticular Distal Radius Fractures, The Journal of Hand Surgery/Jan 2006,Vol: 31 A No.1;01-03.

17. avid P. Green MD, Pins and Plaster Treatment of Comminuted Fractures of Distal end of Radius, British Journal of Bone and Joint Surgery, April 1975, Vol 57 A, No 3, 304-310

18. G. R. Sennwald, Distal Radius Fracture, Palmar or Dorsal Approach? 1995, JHS, 20-A, 1021-27.

\section{Fig. 1: Radiographic variance, radial tilt, inclination and height}

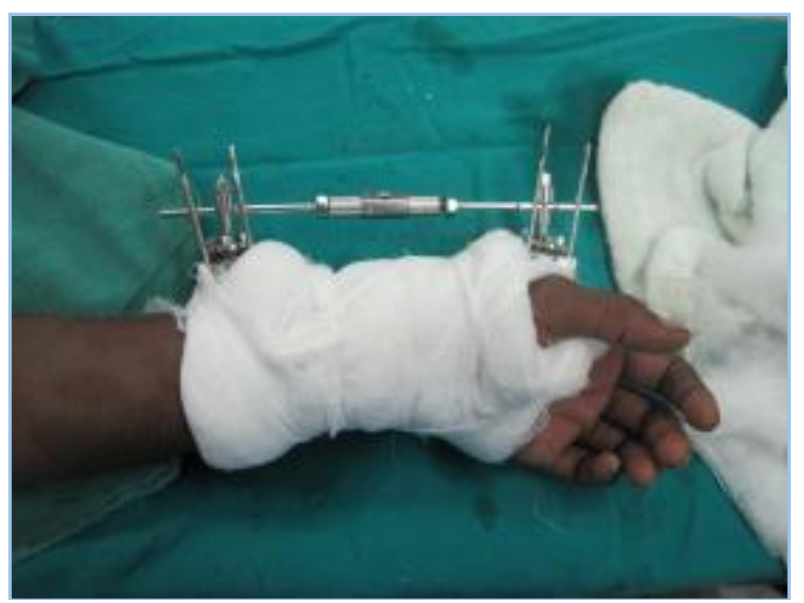

Fig. 2: External fixator/Ligamentotaxis 

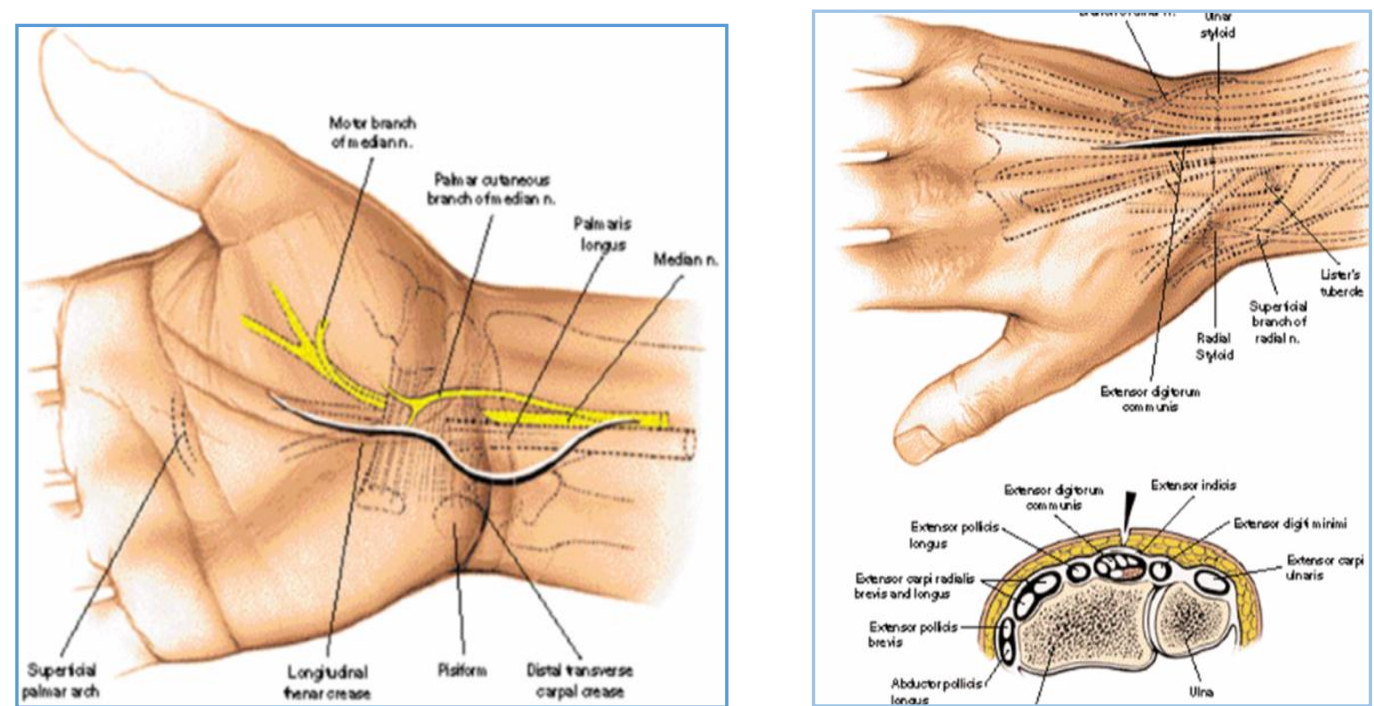

Fig. 3: Volar and Dorsal approaches for buttress plate fixation

\section{NEW YORK ORTHOPAEDIC HOSPITAL WRIST SCORING SYSTEM}

1. MOTION (Percentage of motion):

0-15 POINTS

Dorsi/volar flexion + radio/ulnar deviation+ supiunation/pronation

2. GRIP STRENGTH

PERCENTAGE OF NORMAL

0-15 POINTS

(6-7)

3. RADIOGRAPH

LENGTH MAINTAINED

LOSS OF 0-2 mm

LOSS OF $2-3 \mathrm{~mm}$

LOSS $>5 \mathrm{~mm}$

0-20 POINTS

7
5
3
0

Table 1: NEW YORK ORTHOPAEDIC HOSPITAL WRIST SCORING SYSTEM (NYOHWSS)

\section{B. ARTICULAR SURFACE}

CONGRUENT

INCONGRUENCY 0-1mm

INCONGRUENCY 1-2mm

INCONGRUENCY $>2 \mathrm{~mm}$

5

0

C. JOINT SPACE

NORMAL

DECREASED

NOT APPARENT

\section{DORSAL TILT}

$<20$ DEGREE DORSAL TILT

$>20$ DEGREE DORSAL TILT

\section{SUBJECTIVE}

1. PAIN

A. NONE

B.OCCURS ONLY WITH HEAVY ACTIVITY

C.OCCURS WITH MODERATE ACTIVITY

D.OCCURS WITH LIGHT ACTIVITY

E. PRESENT AT ALL TIMES BUT DOESN'T REQUIRE ANALGESICS

F. PRESENT AT ALL TIMES AND REQUIRES ANALGESICS

\section{0-20 POINTS}

20

16

12

8

4 


\section{FUNCTIONAL}

A. UNLIMITED

B. CAN NO LONGER PARTICIPATE IN HEAVY ACTIVITY

C. CAN NO LONGER PARTICIPATE IN MODERATE ACTIVITY

D. HAS DIFFICULTY DOING LIGHT ACTIVITY

E.USES INJURED HAND AS HELPER

F. NO FUNCTION

The overall scoring was graded as follows:

EXCELLENT: $90-100$

GOOD: $\quad 70-89$

FAIR: $\quad 55-69$

POOR: $\quad<55$

\section{RESULTS:}

Key:

IF = Internal fixation with buttress plate

$\mathrm{EF}=$ External fixation with ligamentotaxis

\begin{tabular}{|c|c|c|c|}
\hline AGE (Years) & IF & EF & Total \\
\hline$<30$ & 12 & 8 & 20 \\
\hline $31-40$ & 18 & 23 & 41 \\
\hline $41-50$ & 9 & 23 & 32 \\
\hline $51-60$ & 12 & 11 & 23 \\
\hline$>61$ & 5 & 11 & 16 \\
\hline Total & $\mathbf{5 6}$ & $\mathbf{7 6}$ & $\mathbf{1 3 2}$ \\
\hline $\begin{array}{r}\text { Table 1: New York Orthopaedic Hospital } \\
\text { Wrist Scoring System (Nyohwss) }\end{array}$
\end{tabular}

\section{Gender Distribution}

\begin{tabular}{|c|c|c|c|}
\hline Sex & IF & EF & Total \\
\hline Male & 37 & 42 & $79(59.8 \%)$ \\
\hline Female & 19 & 34 & $53(40.2 \%)$ \\
\hline Total & $\mathbf{5 6 ( 4 2 . 4 \% )}$ & $\mathbf{7 6 ( 5 7 . 8 \% )}$ & $\mathbf{1 3 2}$ \\
\hline \multicolumn{4}{|c|}{ Table 2: Gender wise distribution of patients } \\
\hline
\end{tabular}

\begin{tabular}{|c|c|c|c|}
\hline Side of Injury & IF & EF & Total \\
\hline Left & 35 & 39 & $74(56.1 \%)$ \\
\hline Right & 21 & 37 & $58(43.9 \%)$ \\
\hline Total & $\mathbf{5 6}$ & $\mathbf{7 6}$ & $\mathbf{1 3 2}$ \\
\hline \multicolumn{4}{|c|}{ Table 3 } \\
\hline
\end{tabular}

Classification of fracture type: Frykman classification

\begin{tabular}{|c|c|c|}
\hline $\begin{array}{c}\text { Frykmans } \\
\text { Type }\end{array}$ & Number & $\begin{array}{c}\text { Percentage } \\
\text { (\%) }\end{array}$ \\
\hline Type 1 & 0 & 0 \\
\hline Type 2 & 0 & 0 \\
\hline Type 3 & 58 & 43.9 \\
\hline Type 4 & 14 & 10.6 \\
\hline Type 5 & 13 & 16.4 \\
\hline Type 6 & 16 & 12.1 \\
\hline Type 7 & 19 & 14.4 \\
\hline Type 8 & 12 & 9.1 \\
\hline Total & $\mathbf{1 3 2}$ & $\mathbf{1 0 0 . 0}$ \\
\hline \multicolumn{2}{|c}{ Table 4: Side of limb involved } \\
\hline
\end{tabular}

\section{0-30 POINTS}

30

25

20

15

10

0

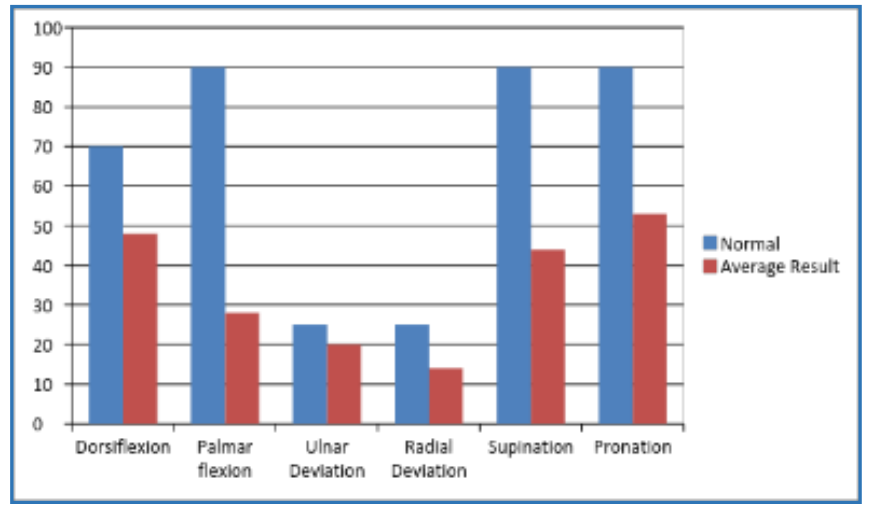

Outcome Scoring of the study (NYOHWSS)

\begin{tabular}{|c|c|c|c|}
\hline NYOHWSS & IF & EF & \% \\
\hline EXCELLENT & 20 & 19 & 31.25 \\
\hline GOOD & 17 & 33 & 40 \\
\hline FAIR & 14 & 10 & 25 \\
\hline POOR & 5 & 14 & 3.75 \\
\hline Total & $\mathbf{5 6}$ & $\mathbf{7 6}$ & \\
\hline \multicolumn{4}{|c|}{$\begin{array}{c}\text { Table 5: Number of patients based } \\
\text { on Frykmans classification }\end{array}$} \\
\hline
\end{tabular}

